\title{
AVALIAÇÃO DO PERIGO DE CONTAMINAÇÃO DO SISTEMA AQUÍFERO GUARANI EM SUA ÁREA DE AFLORAMENTO DO ESTADO DE SÃO PAULO DECORRENTE DAS ATIVIDADES AGRÍCOLAS
}

\author{
POTENTIAL CONTAMINATION RESULTING FROM AGRICULTURAL \\ ACTIVITIES OF THE GUARANI AQUIFER SYSTEM OUTCROPS WITHIN \\ SÃO PAULO STATE
}

Marina Costa Barbosa ${ }^{1}$, Ana Maciel de Carvalho², Priscila Ikematsu³ ${ }^{3}$ José Luiz Albuquerque Filho ${ }^{4}$, Ana Candida Melo Cavani ${ }^{5}$

\begin{abstract}
Resumo A crescente utilização das águas do Sistema Aquífero Guarani (SAG) indica a necessidade de ampliação do conhecimento hidrogeológico e dos aspectos de uso e ocupação do solo nos terrenos correspondentes à área de afloramento desse sistema aquífero, porção mais vulnerável à contaminação. Na área de afloramento do SAG, pode-se identificar um avanço do uso da terra para as atividades agrícolas, fato que justifica uma avaliação do perigo de contaminação da água subterrânea em decorrência dessas atividades. Para tanto foi primeiramente realizado o zoneamento da vulnerabilidade natural do SAG à contaminação e uma classificação do potencial de contaminação de cada tipo de cultura existente na área (cultura anual, perene e semiperene). Em seguida, os mapeamentos foram sobrepostos e, da interpretação dessa sobreposição, elaborou-se o mapa do perigo de contaminação do SAG decorrente das atividades agrícolas. De acordo com os resultados apresentados, a vulnerabilidade à contaminação na área de estudo varia de Média a Alta. A unidade aquífera Botucatu apresenta-se um pouco mais vulnerável que a unidade aquífera Piramboia. Por outro lado, devido às expressivas áreas ocupadas por culturas semiperenes, grande parte da área foi classificada com potencial Elevado de contaminação da água subterrânea. Quanto ao perigo de contaminação, uma área de aproximadamente $2.250 \mathrm{~km}^{2}$ foi classificada com perigo Alto, perfazendo $9 \%$ da área de estudo, o que denota a necessidade de estabelecimento de medidas que priorizem as boas práticas agrícolas e o monitoramento contínuo da qualidade da água. Além disso, constatou-se a necessidade de pesquisas mais detalhadas, uma vez que este estudo foi desenvolvido em caráter regional.
\end{abstract}

Palavras Chave: Sistema Aquífero Guarani (SAG); vulnerabilidade à contaminação; potencialde contaminação decorrente das culturas; perigo de contaminação.

Abstract The increasing water consumption of the Guarani Aquifer System (GAS) indicates the need for expansion of the hydrogeological knowledge and a better understanding of the aspects related to land use in the outcrop of the aquifer system, region more vulnerable to contamination. Land use for agricultural activities is growing in the outcrop of the GAS, which justifies an assessment of the contamination hazard resulted of these activities. To that end, was conducted an evaluation of the GAS natural vulnerability and the potential of contamination by different crops (permanent, semi-permanent and annual crops). Then, the maps were overlaid, what resulted in the contamination aquifer hazard map. According to the results, the natural contamination vulnerability ranges from Medium to High on the studied area. The Botucatu aquifer is a little more vulnerable than the Piramboia aquifer. On the other hand, due to significant areas occupied by semi-perennial crops, the majority of the area was classified as a high potential for groundwater contamination. Concerning to the hazard of contamination, approximately $2,250 \mathrm{~km}^{2}$ were classified as High hazard hazard, representing $9 \%$ of the study area. This study demonstrates the need of measures criteria for good agricultural practices and continuous water quality monitoring process. Moreover, it is necessary more detailed researches, since this was a regional study.

Keywords: Guarani Aquifer System (GAS); natural vulnerability to contamination; potential contamination resulting from agricultural activities; contamination aquifer hazard.

\section{INTRODUÇÃO}

A utilização das águas subterrâneas para o abastecimento público no Brasil é crescente, sendo o Estado de São Paulo, atualmente, o maior usuário do país. Cerca de $80 \%$ dos municípios paulistas são abastecidos, mesmo que parcialmente, por água subterrânea (CETESB, 2010).

No cenário atual, a água subterrânea é uma fonte estratégica para diferentes tipos de usos. Entretanto o seu uso des- controlado e as inadequadas formas de uso e ocupação do solo, podem comprometer a qualidade e a quantidade da água.

A contaminação das águas subterrâneas por pesticidas é um assunto que ganhou interesse mundial a partir da década de 1980, inspirado pela constatação de sua ocorrência, ainda que em baixas concentrações, em diferentes países tais como Grã-Bretanha, Alemanha, Estados Unidos, Grécia, Bulgária, Espanha, Portugal e Brasil (RIBEIRO, 2007).

IPT - Instituto de Pesquisas Tecnológicas do Estado de São Paulo, (albuzelu@ipt.br)

IPT - Instituto de Pesquisas Tecnológicas do Estado de São Paulo, (amaciel@ipt.br)

IPT - Instituto de Pesquisas Tecnológicas do Estado de São Paulo, (priscilai@ipt.br)

IPT - Instituto de Pesquisas Tecnológicas do Estado de São Paulo, (albuzelu@ipt.br)

IPT - Instituto de Pesquisas Tecnológicas do Estado de São Paulo, (anacandi@ipt.br) 
Foster et al. (2006) relatam que algumas práticas de cultivo do solo provocam grave contaminação difusa, principalmente por utilizarem grandes quantidades de fertilizantes e agrotóxicos, sejam eles pesticidas, herbicidas, inseticidas, fungicidas, nematicidas, acaricidas ou formicidas. A contaminação da água subterrânea decorrente de fontes difusas afeta, normalmente, áreas extensas quando comparada à contaminação por fontes pontuais.

Segundo Gomes (2008), no Brasil os agrotóxicos têm sido mais utilizados nas regiões Sudeste (38\%), Sul (31\%) e Centro-Oeste (23\%). O referido autor destaca, ainda, o Estado de São Paulo, que utiliza $25 \%$ do volume total consumido no país.

De acordo com estudos de Foster et al. (2002), as áreas agrícolas ocupam $83 \%$ do território paulista, com predomínio do cultivo de cana de açúcar, café, cítricos e milho. Com o processo de expansão das áreas cultivadas e visando o aumento da produtividade incrementou-se o uso de fertilizantes e agrotóxicos no Estado cujos compostos apresentam grande mobilidade na água subterrânea.

Extensas parcelas da área de afloramento do Sistema Aquífero Guarani (SAG) no Estado de São Paulo têm sido ocupadas pelas atividades agrícolas (GOMES, 2008). O mapeamento do uso e ocupação do solo para todo o Estado de São Paulo (SMA, 2009) indica que a categoria culturas representa uma porcentagem significativa das atividades desenvolvidas nessa região.

Somada a essa situação, de acordo com o mapeamento da vulnerabilidade e risco de poluição das águas subterrâneas no Estado de São Paulo, desenvolvido por IG/Cetesb/ DAEE (HIRATA et al., 1997), na escala 1: 500.000 e editado em 1: 1.000.000, os maiores índices de vulnerabilidade predominam em alguns aquíferos, entre eles o Botucatu e o Piramboia, que constituem o SAG, onde, respectivamente, 55\% e 50\% de área apresentam índices de Alta Vulnerabilidade.

A caracterização do risco de poluição das águas subterrâneas no Estado de São Paulo efetuada no âmbito do estudo citado anteriormente (HIRATA et al., 1997) compreendeu a análise integrada do mapeamento da vulnerabilidade com a classificação de cargas poluidoras pontuais e difusas. Os resultados desses estudos indicaram que as áreas de maior preocupação ambiental concentram-se na área de afloramento do SAG e de alguns municípios, recomendando-se priorizar estudos de detalhamento nessas áreas.

Uma vez que a área de afloramento do SAG constitui-se de terrenos naturalmente vulneráveis à eventual infiltração de contaminantes e que existe uma crescente utilização dessas áreas para as atividades agrícolas, faz-se necessário uma avaliação regional do perigo de contaminação do SAG relacionado ao desenvolvimento dessas atividades.

O perigo de contaminação representa a ameaça de um aquífero sofrer impactos negativos decorrentes de determinada atividade humana em tal nível que a água subterrânea se torne imprópria para o consumo. Essa avaliação é efetuada integrando-se a vulnerabilidade natural do aquífero à contaminação com o potencial de contaminação das atividades que ocorrem em superfície (FOSTER et al., 2006).

A compreensão dos resultados da caracterização do perigo de contaminação é essencial para a proteção dos aquíferos, pois possibilita a identificação de locais que podem sofrer contaminação da água com maior facilidade, indicando, assim, onde devem ser aplicadas as medidas prioritárias de proteção e controle.

As iniciativas de planejamento e ordenamento do território e de gestão dos recursos hídricos necessitam desse tipo de instrumento para efetivar as ações voltadas ao disciplinamento do uso e ocupação do solo na área de afloramento do SAG no Estado de São Paulo e, por conseguinte, ampliar a proteção das áreas de recarga do aquífero. Portanto, a aplicação dessa ferramenta contribui para a gestão regional, indicando a existência, ou não, de culturas em locais que podem prejudicar a qualidade da água do SAG e promovendo a identificação das zonas mais sensíveis a certos tipos de atividades.

Este trabalho faz parte da pesquisa desenvolvida pelo IPT (2010), a qual compreendeu a realização de diagnóstico e estabelecimento de subsídios para a elaboração do plano de desenvolvimento e proteção ambiental na área de afloramento do SAG.

\section{ÁREA DE ESTUDO}

O SAG é um corpo hídrico subterrâneo, transfronteiriço, sendo considerado um dos maiores reservatórios de água subterrânea do mundo e estendendo-se por uma área de aproximadamente $1.087 .879 \mathrm{~km}^{2}$. A maior parcela do SAG está localizada em território brasileiro (71\%), abrangendo parte de oito estados das regiões sul, sudeste e centro-oeste do país (OEA, 2009).

No Estado de São Paulo a área de ocorrência do SAG ocupa aproximadamente $143.000 \mathrm{~km}^{2}$ (OEA, 2009), sendo o aquífero regionalmente livre na sua porção aflorante, com cerca de $15.000 \mathrm{~km}^{2}$ a dominantemente confinado, com aproximadamente $128.000 \mathrm{~km}^{2}$ de área.

As formações geológicas que constituem o SAG datam de cerca de 130 milhões de anos e no Brasil compreendem a Formação Piramboia, correspondendo à porção basal, e a Formação Botucatu, o topo. A característica de confinamento do SAG se dá devido à presença de camadas constituídas por rochas basálticas, da Formação Serra Geral, que ocorrem superpondo as camadas que compõem o Sistema e, também, de rochas sedimentares de baixa permeabilidade, da Formação Passa Dois, que ocorrem na base.

A delimitação da área de estudo efetuada pelo IPT (2010) considerou o limite da porção aflorante do SAG no Estado de São Paulo (formações Botucatu e Piramboia), de acordo com o Mapa Geológico na escala 1: 250.000 (convênio DAEE/UNESP, 1980), tendo sido acrescentada uma faixa de segurança de 2,0 km de largura (buffer) ao longo do perímetro da região de ocorrência superficial das duas formações.

Vale destacar que a área de estudo foi delimitada de 


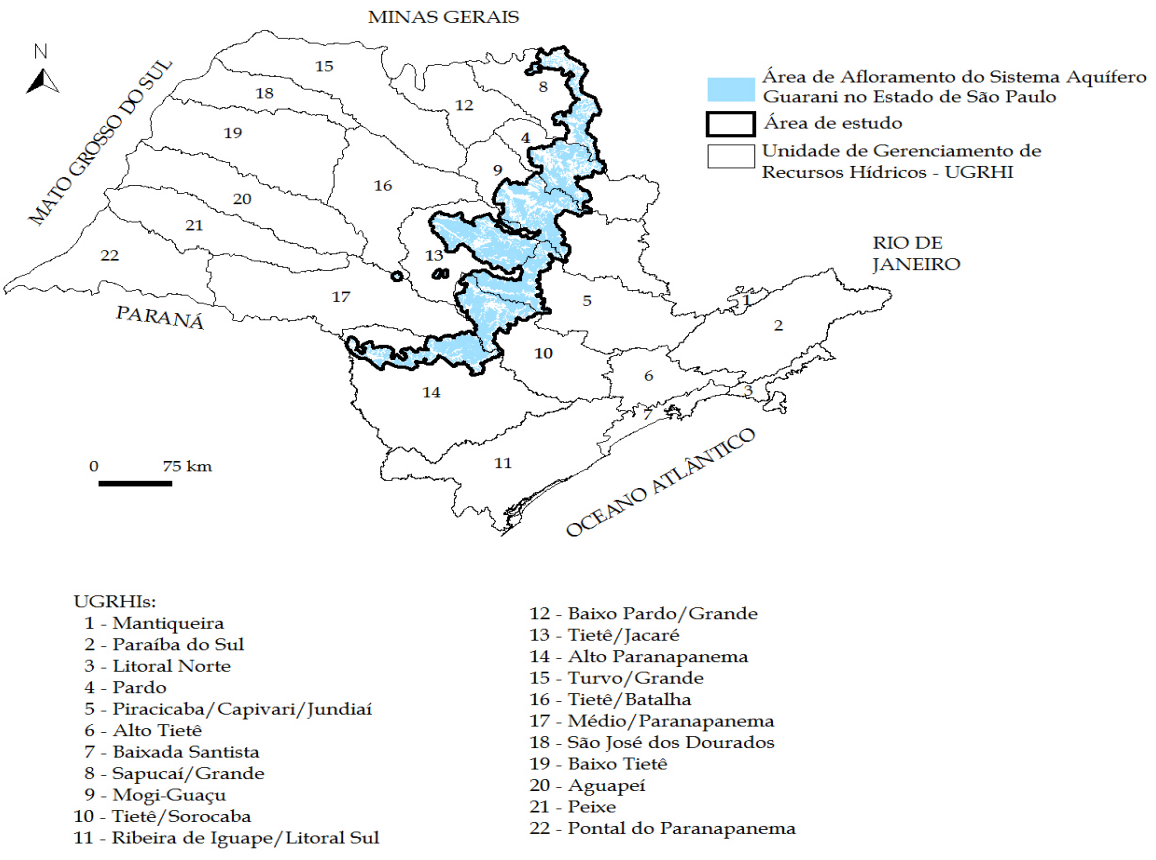

Figura 1. Área de estudo.

acordo com a ocorrência de um manancial subterrâneo e não a partir de limites de bacias hidrográficas ou limites municipais. Nesse sentido, envolve, mesmo que parcialmente, 105 municípios do Estado de São Paulo e 7 Unidades de Gerenciamento de Recursos Hídricos (UGRHIs), quais sejam, UGRHI 4 - Pardo, UGRHI 5 - Piracicaba/ Capivari/Jundiaí, UGRHI 8 - Sapucaí/Grande, UGRHI 9 - Mogi-Guaçu, UGRHI 10 - Tietê/Sorocaba, UGRHI 13 - Tietê/Jacaré e UGRHI 14 - Alto Paranapanema, totalizando uma área de aproximadamente $26.110 \mathrm{~km}^{2}$. Assim sendo, considerando-se as dimensões da área de estudo, a avaliação do perigo de contaminação decorrente das atividades agrícolas foi efetuada em caráter regional.

\section{MATERIAIS E MÉTODOS}

O perigo de contaminação foi caracterizado por meio da análise integrada do zoneamento da vulnerabilidade natural à contaminação frente à classificação do potencial de contaminação dos diferentes tipos de cultura existentes na área de estudo. Foi utilizado o software Mapinfo ${ }^{\circledR}$ na versão 10.0 (GEOGRAPH, 2009) para a elaboração dos mapas temáticos.

Zoneamento da vulnerabilidade natural do SAG à contaminação. $\mathrm{O}$ conceito de vulnerabilidade à contaminação foi introduzido no início da década de 70, na França, por Albinet \& Margat (1970), para avaliar o grau de proteção que o ambiente natural fornece contra o acesso de contaminantes às águas subterrâneas. A determinação da vulnerabilidade natural do aquífero está relacionada, portanto, à acessibilidade de contaminantes à zona saturada e à capacidade de atenuação dos estratos de cobertura da zona saturada, resultante da retenção fisioquímica ou da reação dos contaminantes com o meio (FOSTER et al., 2006).

Existem vários métodos de avaliação de vulnerabilidade natural de aquíferos: o método GOD (FOSTER \& HIRATA, 1988); o DRASTIC (ALLER et al., 1987); o método da Poluição dos Lençóis Aquíferos (TALTASSE, 1972); Mapa de Vulnerabilidade (DUARTE, 1980); SINTACS (CIVITA et al., 1990); entre outros.

Tendo em vista objetivos práticos, a utilização de um método mais genérico e menos detalhado é importante, por produzir apenas um mapa integrado da vulnerabilidade (FOSTER \& HIRATA, 1988). Avalia-se, entretanto, que esse método deve ser usado com certa cautela, particularmente em situações que existam informações de detalhe.

O método GOD, que vem sendo utilizado atualmente com maior frequência no Brasil, é um método de simplicidade conceitual (FOSTER, 1987; FOSTER e HIRATA, 1988, apud FOSTER et al., 2006) e se mostrou compatível com o objetivo pretendido, qual seja, elaborar um mapa integrado da vulnerabilidade natural do SAG à contaminação em sua porção aflorante na escala de mapeamento geológico disponível (1: 250.000) e avaliar o perigo de contaminação nessa região (IPT, 2010).

O método GOD consiste na avaliação de três fatores hidrogeológicos - grau de confinamento da água subterrânea $(\mathrm{G})$; ocorrência de estratos de cobertura $(\mathrm{O})$; e distância 


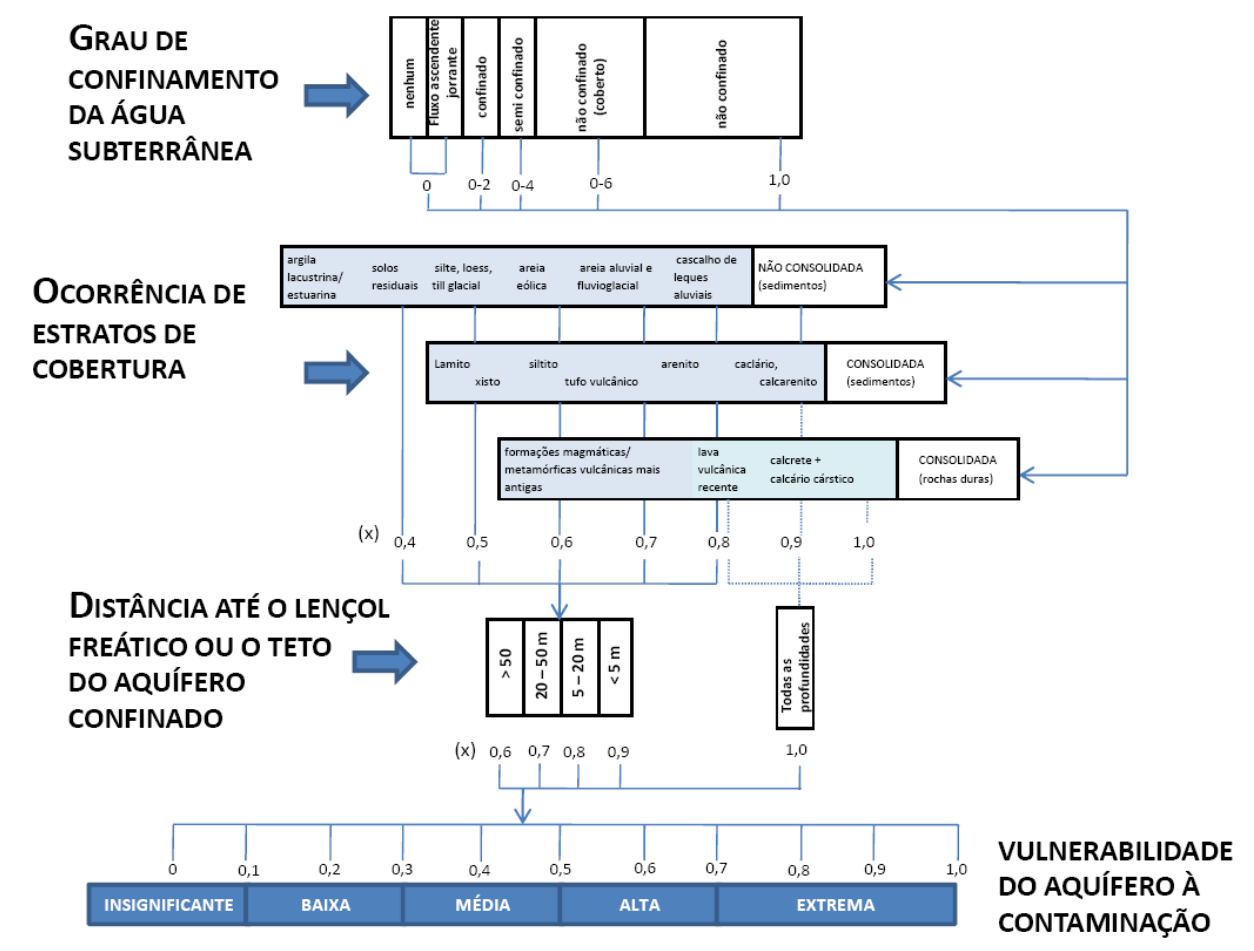

Fonte: Foster et al. (2006)

Figura 2. Matriz do método GOD para avaliação da vulnerabilidade do aquífero à contaminação.

Quadro 1. Definição prática das classes de vulnerabilidade do aquífero.

\begin{tabular}{|c|c|}
\hline $\begin{array}{c}\text { Classe de } \\
\text { Vulnerabilidade }\end{array}$ & Definição correspondente \\
\hline Extrema & Vulnerável à maioria dos contaminantes com impacto rápido em muitos \\
cenários de contaminação.
\end{tabular}

Fonte: Foster et al. ( 2006).

até o nível freático da água subterrânea (D) - geralmente disponíveis ou facilmente determinados (FOSTER, 1987; FOSTER e HIRATA, 1988, apud FOSTER et al., 2006).

Considerando as características hidrogeológicas dos aquíferos, se estabelece uma pontuação para cada fator avaliado (Figura 2). A vulnerabilidade natural do aquífero à contaminação é obtida pela multiplica- ção da pontuação estabelecida para os três fatores sendo subdividida em diferentes categorias, a saber: Extremo, Alto, Médio, Baixo e Insignificante (Quadro 1).

Para a aplicação do método GOD foram avaliadas as unidades mais vulneráveis da área de estudo, segundo Hirata et al. (1997), quais sejam: as formações geológicas Botucatu e Piramboia; e, também, os depósitos aluviona- 
res, por constituírem camadas pouco espessas localizadas sobre o SAG (IPT, 2010). Foi utilizado como base o Mapa Geológico do Estado de São Paulo, elaborado na escala 1: 250.000 (Convênio DAEE/Unesp, 1980), por ser a informação disponível que apresenta maior detalhamento.

Os demais aquíferos que ocorrem na área de estudo não foram avaliados, pois, devido a suas características litológicas, se caracterizam como aquíferos menos vulneráveis, segundo Hirata et al. (1997) e, também, não se incluíam nos objetivos da pesquisa do IPT (2010).

Além disso, não foram classificadas as regiões na porção confinada do SAG onde ocorrem descontinuidades no basalto e onde os sedimentos do SAG ficam em contato direto com a superfície, conhecidas como "janelas" no basalto, uma vez que se referem a pequenas áreas de afloramento do sistema, estando isoladas e separadas do polígono principal, representando uma pequena porcentagem na área de estudo do estudo do IPT (2010).

$\mathrm{Na}$ aplicação do método GOD, o grau de confinamento (G) foi determinado conforme estudos regionais do SAG realizado por DAEE/IG/IPT/CPRM em Rocha (2005) e IG/Cetesb/DAEE (HIRATA et al., 1997), que classificam o SAG como um sistema granular, homogêneo e regionalmente livre, ou seja, não confinado na sua porção aflorante. Aquíferos não confinados são mais vulneráveis à contaminação e, portanto, recebem uma pontuação Alta na escala de avaliação do grau de confinamento, que varia de 0 a 1,0. Por serem semelhantes quanto a esse fator, tanto a Formação Botucatu quanto a Formação Piramboia receberam a pontuação 0,9.

Para a determinação da pontuação para o fator ocorrência de estratos de cobertura (O) utilizou-se o Mapa Geológico do Estado de São Paulo, elaborado na escala 1: 250.000 (Convênio DAEE/Unesp, 1980). A Formação Botucatu é constituída por arenitos de granulação fina a média, avermelhados, com grãos de Alta esfericidade e bem selecionados, consequentes de dunas eólicas (IPT, 1981). Já a Formação Piramboia é constituída por arenitos de granulação fina a média, localmente grossos e conglomeráticos, com fácies sedimentares que apresentam silte e argila depositados em ambiente fluvio-lacustrino e eólico (CAETANO-CHANG \& WU, 1992; MILANI et al., 1994; GIANINI et al., 2004).

Pelo método GOD, a escala de pontuação para o fator ocorrência do estrato de cobertura $(\mathrm{O})$ varia de 0,4 a 1,0. Nesse sentido, levando-se em consideração as características da Formação Botucatu, o grau de consolidação sobre o estrato de cobertura dessa formação é menor se comparado à Formação Piramboia, pois as características litológicas não permitem uma boa capacidade de atenuação da contaminação. Assim, para esse fator, a Formação Botucatu é ligeiramente mais vulnerável que a Formação Piramboia, recebendo a pontuação 0,8. Já a Formação Piramboia, recebeu a pontuação 0,7.

A avaliação do fator relacionado à distância até o nível freático da água subterrânea (D) possui importância fundamental. Isso porque, quando se trata de um mes- mo sistema aquífero, pequenas alterações na distância até o nível freático alteram significativamente o índice da vulnerabilidade. Nesse sentido, sabe-se que os níveis mais rasos permitem que o contaminante alcance rapidamente à zona saturada, devido à menor distância que o contaminante deve percorrer da superfície ao aquífero.

No método GOD o intervalo de pontuação para a profundidade do nível freático varia de 0,6 a 1,0, onde a distância menor recebe pontuação maior, pois uma possível contaminação alcança mais rápido o aquífero quando este está mais raso, tornando-o mais vulnerável.

Para delimitar a distância até o nível freático (D) na área de estudo foram avaliados, inicialmente, os valores de profundidade de nível estático de poços localizados na região construídos na década de 2000 e com valores de profundidade de nível estático medidos em campanha de cadastramento de poços, ocorrida no ano de 2009, totalizando 127 poços com informação (IPT, 2010).

No entanto, como a quantidade de poços não foi suficiente para elaborar um mapa de nível da água subterrânea em toda a área de afloramento do SAG no Estado de São Paulo, os intervalos de nível estático foram associados aos intervalos de cotas topográficas observadas nos mapas em escala 1 : 250.000 da região. Isso porque, de maneira geral, pode-se considerar que as cotas topográficas mais baixas estão relacionadas com os níveis estáticos mais rasos. Essa associação foi feita para as sub-bacias, delimitadas considerando-se os rios de maior porte da área em estudo, quais sejam, o rio Grande, o rio Sapucaí, o rio Pardo, o rio Mogi-Guaçu, o rio Tietê e dois afluentes, e o rio Paranapanema, como exutórios subterrâneos principais da região de interesse.

A Tabela 1 apresenta a ponderação de cada fator avaliado, assim como a classificação da vulnerabilidade natural do aquífero à contaminação, resultante do produto dos valores atribuídos para o grau de confinamento $(\mathrm{G})$, para a ocorrência do estrato de cobertura $(\mathrm{O})$ e para a distância até o nível freático (D).

Vale destacar que os depósitos aluvionares foram classificados, em sua totalidade, com o índice Alto-alto de vulnerabilidade, devido às suas características, como constituição arenosa, ser de caráter livre, e por se apresentar na forma de camadas pouco espessas.

\section{CLASSIFICAÇÃO DO POTENCIAL DE CONTAMI- NAÇÃO DAS CULTURAS}

Para a avaliação e a classificação das culturas, como fontes difusas potenciais de contaminação da água subterrânea, utilizou-se os níveis qualitativos do método POSH, acrônimo em inglês de pollutant origin, surcharge hydraulically (FOSTER et al., 2006) e a classificação dos Domínios Pedomorfoagroclimáticos proposta pela Embrapa (GOMES, 2008).

$\mathrm{O}$ método POSH classifica em três níveis qualitativos o potencial para gerar uma carga contaminante no subsolo (Reduzido, Moderado e Elevado) e baseia-se na origem do po- 

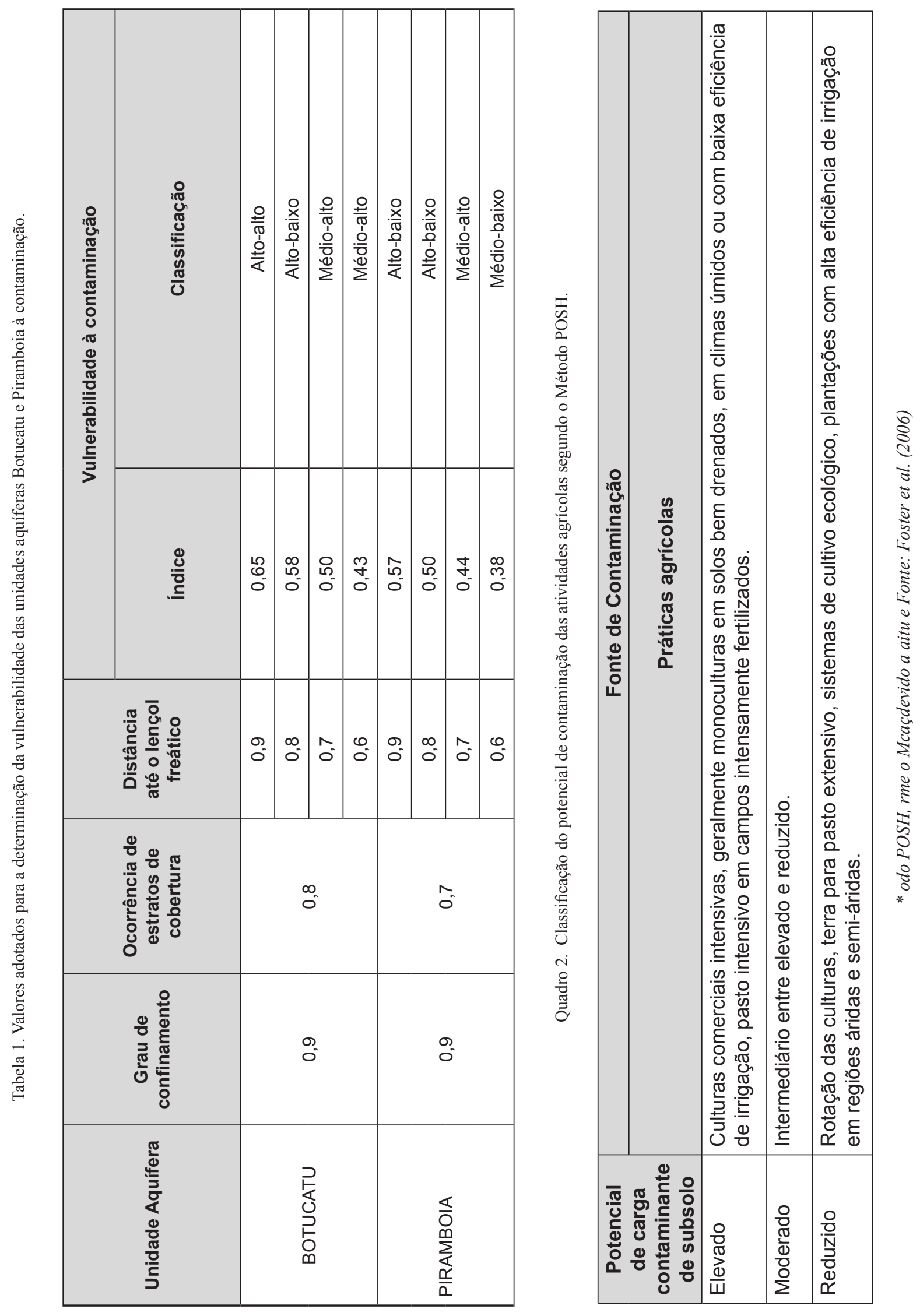


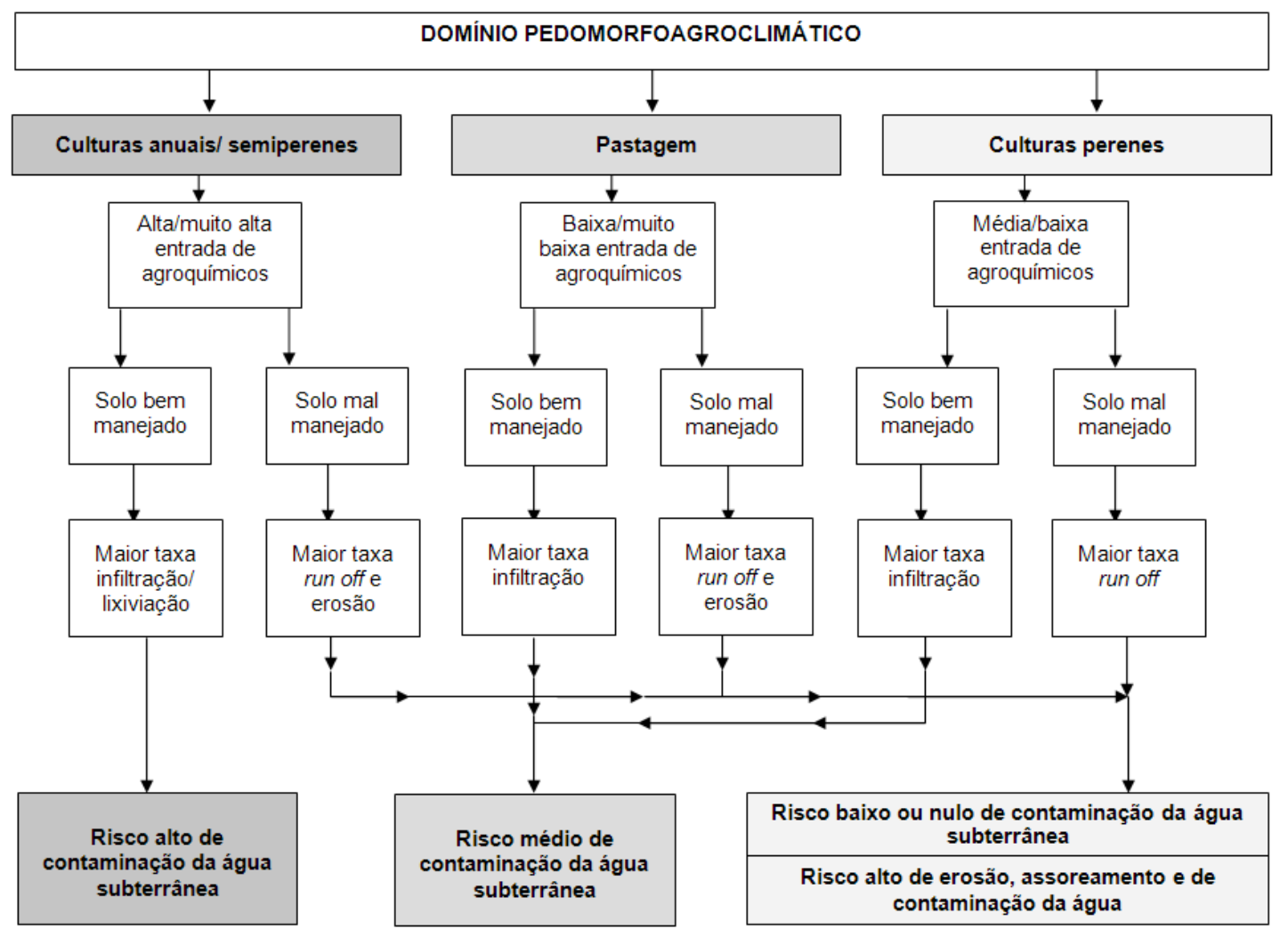

Fonte: Gomes (2008).

Figura 3. Determinação do risco de contaminação da água subterrânea.

luente e na sua sobrecarga hidráulica (FOSTER et al., 2006).

Por sua vez, o princípio do método apresentado por Gomes (2008) é classificar os riscos de contaminação das águas subterrâneas conforme as atividades agrícolas existentes (culturas), considerando a entrada potencial de agroquímicos no solo e a qualidade do manejo praticado, o qual pode resultar em maior ou menor taxa de lixiviação/infiltração.

O Quadro 2 ilustra a classificação das práticas agrícolas conforme o Método POSH e a Figura 3 apresenta o fluxograma proposto por Gomes (2008) para a classificação da criticidade de acordo com o tipo de cultura.

O mapeamento do uso e ocupação do solo, que mostra a delimitação das culturas anuais, perenes e semiperenes na área de estudo, corresponde ao estudo da SMA (2009), o qual foi utilizado para a classificação do potencial de contaminação das atividades agrícolas.

Conforme o Método POSH as culturas presentes na área poderiam ser classificadas com potencial Elevado de contaminação, devido ao clima úmido da região e à adoção de culturas intensivas, geralmente monoculturas. O Método proposto por Gomes (2008), por sua vez, distingue as culturas em anuais, perenes ou semiperenes. Adotando-se a classificação do Mapa de Uso e Ocupação do Solo observa-se que as mesmas, segundo Gomes (2008), poderiam ser classificadas como risco alto ou médio de contaminação da água subterrânea devido à prática adotada, em geral, de solo bem manejado.
Dessa forma, o Quadro 3 sintetiza a classificação proposta no presente trabalho das atividades agrícolas como fontes difusas potenciais de contaminação do SAG.

\section{AVALIAÇÃO DO PERIGO DE CONTAMINAÇÃO DO SAG DECORRENTE DAS CULTURAS}

O termo "perigo de contaminação da água subterrânea" empregado neste trabalho tem o mesmo significado que "risco de contaminação da água subterrânea" utilizado por vários outros autores. A mudança de termo foi proposta por Foster et al. (2006) para adequar-se àquela ora utilizada por outras áreas de avaliação de riscos a ecossistemas e à saúde humana e animal, onde risco é agora definido como o produto de "perigo vezes escala do impacto", ressaltando-se que o presente trabalho se restringe à avaliação do perigo de contaminação da água subterrânea.

O perigo de contaminação é definido como a probabilidade de que a água de um aquífero atinja níveis inaceitáveis de contaminação em decorrência das atividades que se realizam na porção imediatamente acima da superfície do solo (FOSTER \& HIRATA, 1988; ADAMS \& FOSTER, 1992).

A avaliação do perigo envolve, portanto, a análise integrada entre resultados obtidos no mapeamento da vulnerabilidade com os resultados do zoneamento das fontes potencialmente contaminantes doaquífero. Os casos mais preocupantes são aqueles em que as atividades capazes de gerar elevada 
Quadro 3. Método Proposto para a classificação do potencial de contaminação das atividades agrícolas, na área de estudo.

\begin{tabular}{|c|c|}
\hline Atividades agrícolas & $\begin{array}{c}\text { Potencial de carga } \\
\text { contaminante }\end{array}$ \\
\hline $\begin{array}{c}\text { Culturas anuais e Culturas } \\
\text { semiperenes }\end{array}$ & Elevado \\
\hline Culturas perenes & Moderado \\
\hline
\end{tabular}

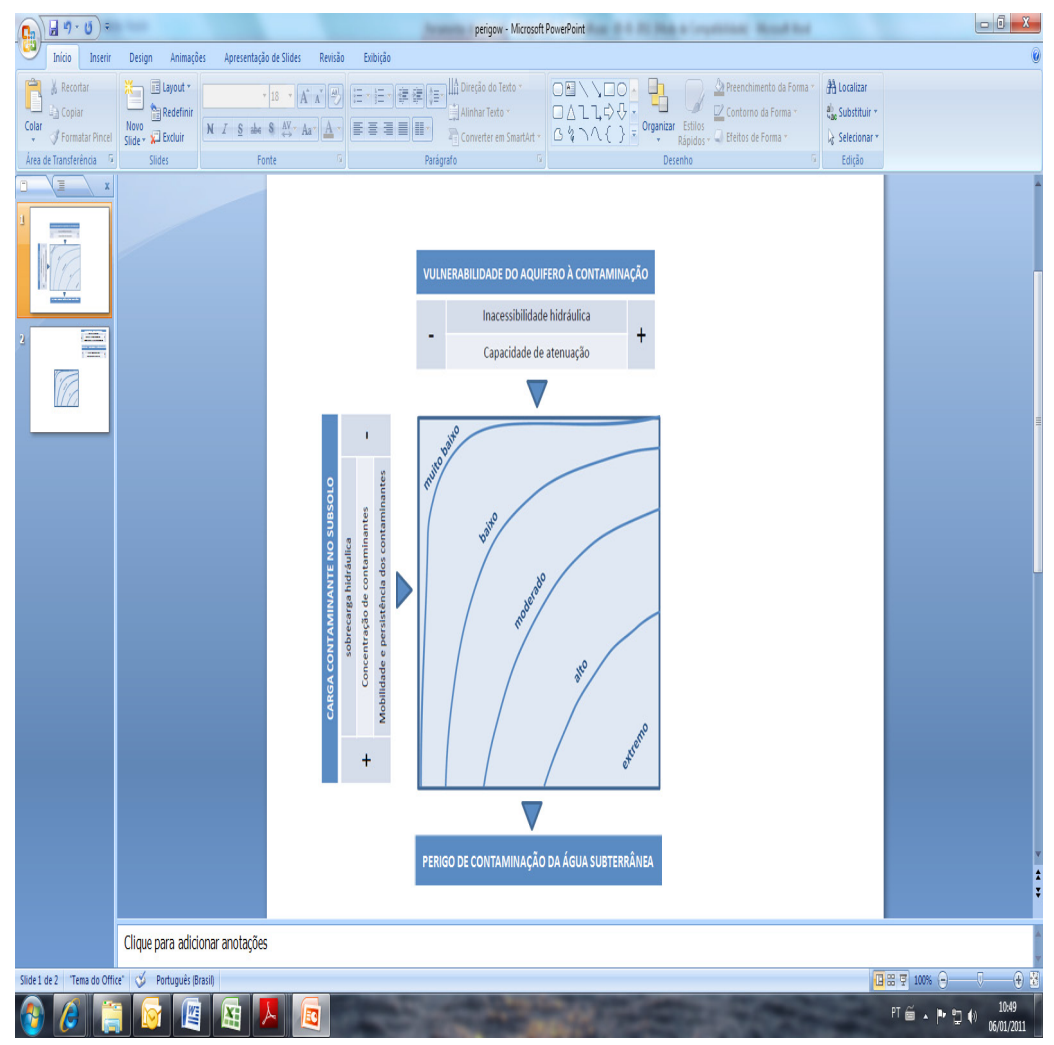

Fonte: Foster et al., (2006).

Figura 4. Avaliação do perigo de contaminação da água subterrânea.

carga contaminante ocorrem em uma área de Alta ou Extrema vulnerabilidade do aquífero, como mostra a Figura 4.

Para a avaliação do perigo de contaminação decorrente das atividades agrícolas foi proposta a classificação apresentada no Quadro 4. É importante destacar que, na área estudada, os mapeamentos disponíveis abordam apenas a presença de culturas perenes e semiperenes que, segundo a classificação proposta pelo método POSH e Gomes (2008), podem ser classificadas como Elevado e Moderado potencial de contaminação. Assim sendo, o método proposto pode ser utilizado, também, em outros casos, onde sejam avaliadas fontes de contaminação que podem ser enquadradas no nível Reduzido.

\section{DISCUSSÃO DOS RESULTADOS}

$\mathrm{Na}$ área de estudo, a vulnerabilidade à contaminação variou de Média a Alta, sendo que essas classes foram subdivididas em dois subníveis (Alto e Baixo), existindo, portanto, quatro classes de vulnerabilidade, a saber:
Alto-alto; Alto-baixo; Médio-alto; e Médio-baixo. Os resultados demonstraram que o índice para a unidade aquífera Botucatu varia de Alto-alto a Médio-alto e para a unidade aquífera Piramboia varia de Alto-baixo a Médio-baixo, comprovando que a unidade aquífera Botucatu se apresenta um pouco mais vulnerável (Figura 5).

A área das classes de vulnerabilidade na região estudada está apresentada na Tabela 2.

Observa-se, assim, que, aproximadamente, $4.000 \mathrm{~km}^{2}$ da área de estudo se configuram como áreas de Alta vulnerabilidade à contaminação e que cerca de $12.000 \mathrm{~km}^{2}$ apresentam índice médio de vulnerabilidade. Observando-se a área mapeada (Figura 5), percebe-se que o índice Alto ocorre nas margens das principais drenagens, onde a profundidade do nível d'água subterrânea é menor do que $20 \mathrm{~m}$.

Vale ressaltar que os resultados ora apresentados retratam uma avaliação da vulnerabilidade natural do SAG à contaminação, na sua área de afloramento no Estado 
Quadro 4. Método Proposto para a classificação do perigo de contaminação.

\begin{tabular}{|c|c|c|c|c|c|}
\hline & & Potencial de & ntaminaçã & & \\
\hline $\begin{array}{c}\text { Índice de Vulnerabilidade } \\
\text { Natural }\end{array}$ & Elevado & Moderado & Reduzido & $\begin{array}{l}\text { Não identificado } \\
\text { (Outras fontes)** }\end{array}$ & \\
\hline Alto-alto & \multirow{2}{*}{ Alto } & \multirow{2}{*}{ Alto } & \multirow{2}{*}{ Moderado } & \multirow{2}{*}{ Não determinado } & $\underline{\varepsilon}$ \\
\hline Alto-baixo & & & & & \\
\hline Médio-alto & \multirow{2}{*}{ Alto } & \multirow{2}{*}{ Moderado } & \multirow{2}{*}{ Baixo } & \multirow{2}{*}{ Não determinado } & 8 \\
\hline Médio-baixo & & & & & \\
\hline $\begin{array}{l}\text { Não Definido (unidades } \\
\text { não mapeadas)* }\end{array}$ & $\begin{array}{c}\text { Não } \\
\text { determinado }\end{array}$ & $\begin{array}{c}\text { Não } \\
\text { determinado }\end{array}$ & Não & Não determinado & \\
\hline
\end{tabular}

* Área não classificada na Carta de Zoneamento da Vulnerabilidade à Contaminação da área de estudo. ** Fonte potencial de contaminação (cultura) não existente ou não mapeada na Carta de Classificação das Fontes Difusas de Contaminação das Águas Subterrâneas na área de estudo.

Tabela 2. Classificação da vulnerabilidade à contaminação na área de estudo.

\begin{tabular}{|c|c|c|}
\hline Unidades & Classificação & Área $\mathbf{( k m}^{\mathbf{2}} \mathbf{~}$ \\
\hline \multirow{3}{*}{$\begin{array}{c}\text { SAG e depósitos } \\
\text { aluvionares }\end{array}$} & Alto-alto & 988 \\
\cline { 2 - 3 } & Alto-baixo & 2.849 \\
\cline { 2 - 3 } & Médio-alto & 8.927 \\
\cline { 2 - 3 } & Médio-baixo & 3.066 \\
\cline { 2 - 3 } & TOTAL & 15.830 \\
\hline Outras & Não definido & 10.270 \\
\hline
\end{tabular}

de São Paulo, realizada em escala regional. É fundamental, portanto, o desenvolvimento de estudos em escalas de maior detalhe, principalmente nos locais já identificados como de Alta vulnerabilidade à contaminação.

A Figura 6, por sua vez, apresenta o resultado do zoneamento do potencial de contaminação da água subterrânea na área de estudo decorrente das atividades agrícolas. Observa-se que $91 \%$ das áreas de cultura, de acordo com o Mapa de Uso e Ocupação do Solo (SMA, 2009), foram classificadas com potencial Elevado de contaminação da água subterrânea. Isso decorre, principalmente, da parcela significativa das áreas de cultura semiperene com o predomínio do cultivo de cana de açúcar e o bom manejo agrícola associado favorecendo, portanto, a drenabilidade e infiltração dos fertilizantes e biocidas utilizados.

Considerando a extensão da área de estudo e o número de municípios envolvidos, destacam-se São Carlos, Luis Antônio, Altinópolis e Descalvado, que juntos possuem, aproximadamente, $18 \%$ da área de cultura classificada com Elevado potencial de contaminação da água subterrânea.

A sobreposição do mapa do zoneamento da vulnerabilidade do SAG à contaminação ao mapa da classificação do potencial de contaminação das culturas possibilitou a elaboração do mapa do perigo de contaminação da área de afloramento do SAG no Estado de São Paulo decorrente das atividades agrícolas (Figura 7). A Tabela 3 apresenta as classes de perigo observadas na área estudada.

A Tabela 3 mostra a ocorrência de área de cerca de 2.250 $\mathrm{km}^{2}$ classificada como Alto perigo de contaminação por fontes difusas, no caso, atividades agrícolas. Ao mesmo tempo nota-se que existe uma significativa parcela da área classificada como perigo "Não Determinado", correspondente às áreas "Não Definidas" no zoneamento da vulnerabilidade e aos locais onde não ocorre ou não foram mapeadas fontes difusas de contaminação, no caso as práticas agrícolas.

Essa situação retrata o caráter regional do estudo do IPT (2010), que representa uma primeira avaliação do perigo de contaminação da água subterrânea para a área de afloramento do SAG no Estado de São Paulo, mas ao mesmo tempo identifica áreas prioritárias, principalmente, no que se refere à necessidade de realização de estudos em escala de maior detalhe e investigações visando o monitoramento da qualidade das águas subterrâneas e adoção de medidas de gestão e gerenciamento, que possibilitem a adequada proteção do SAG em sua área de afloramento/recarga. 


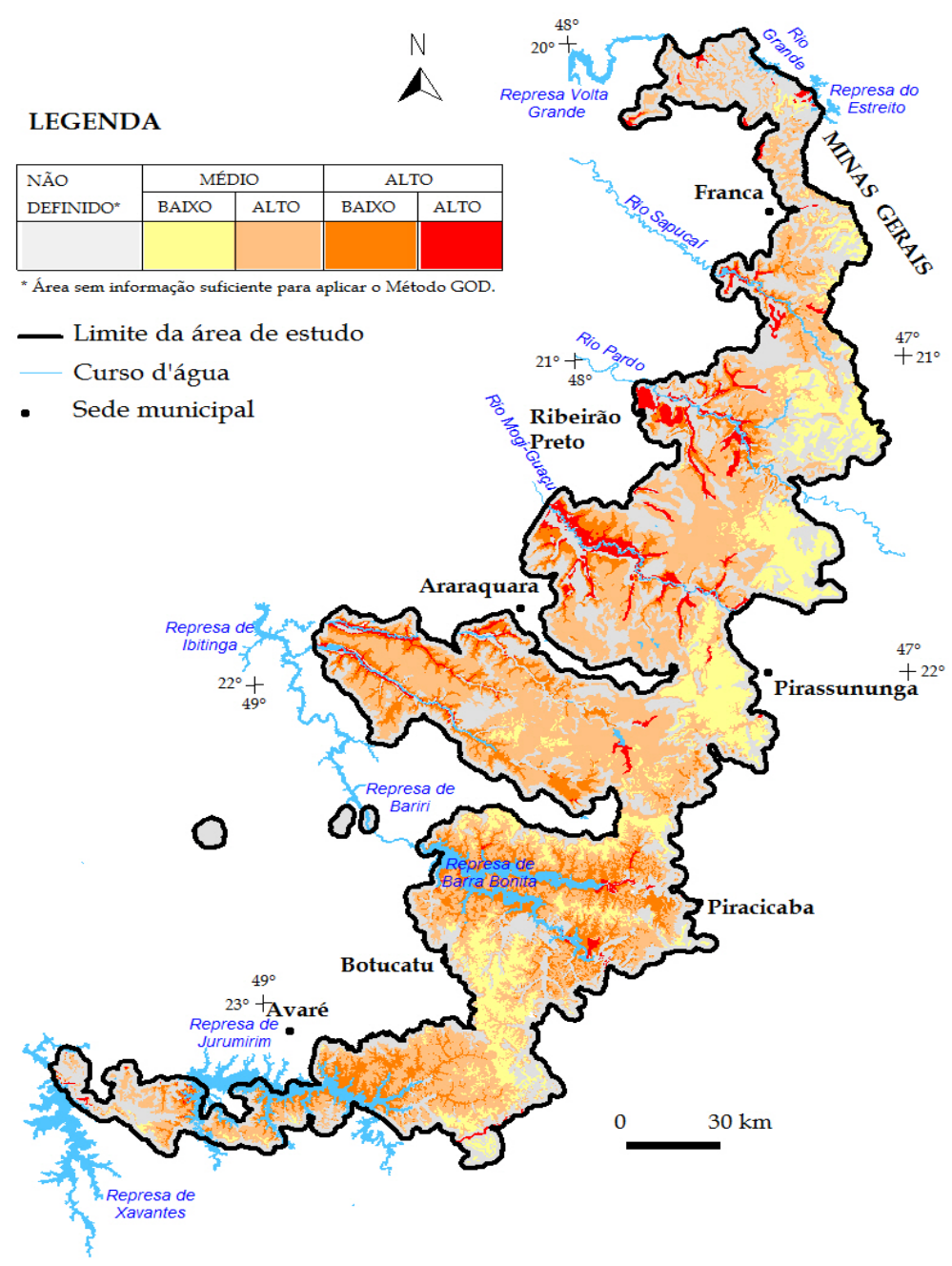

Figura 5. Vulnerabilidade natural do SAG à contaminação. 


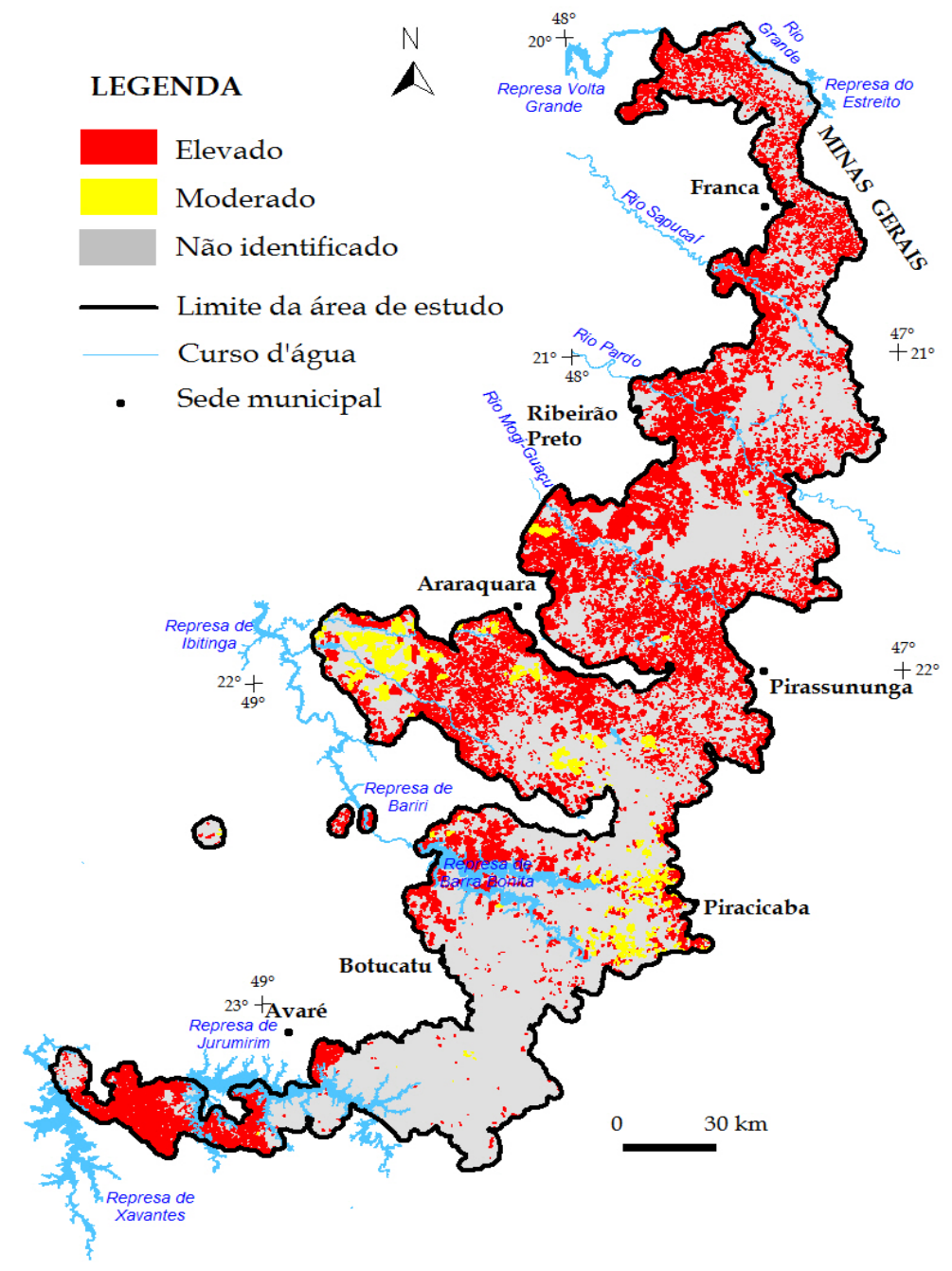

Figura 6. Fontes difusas potenciais de contaminação das águas subterrâneas. 


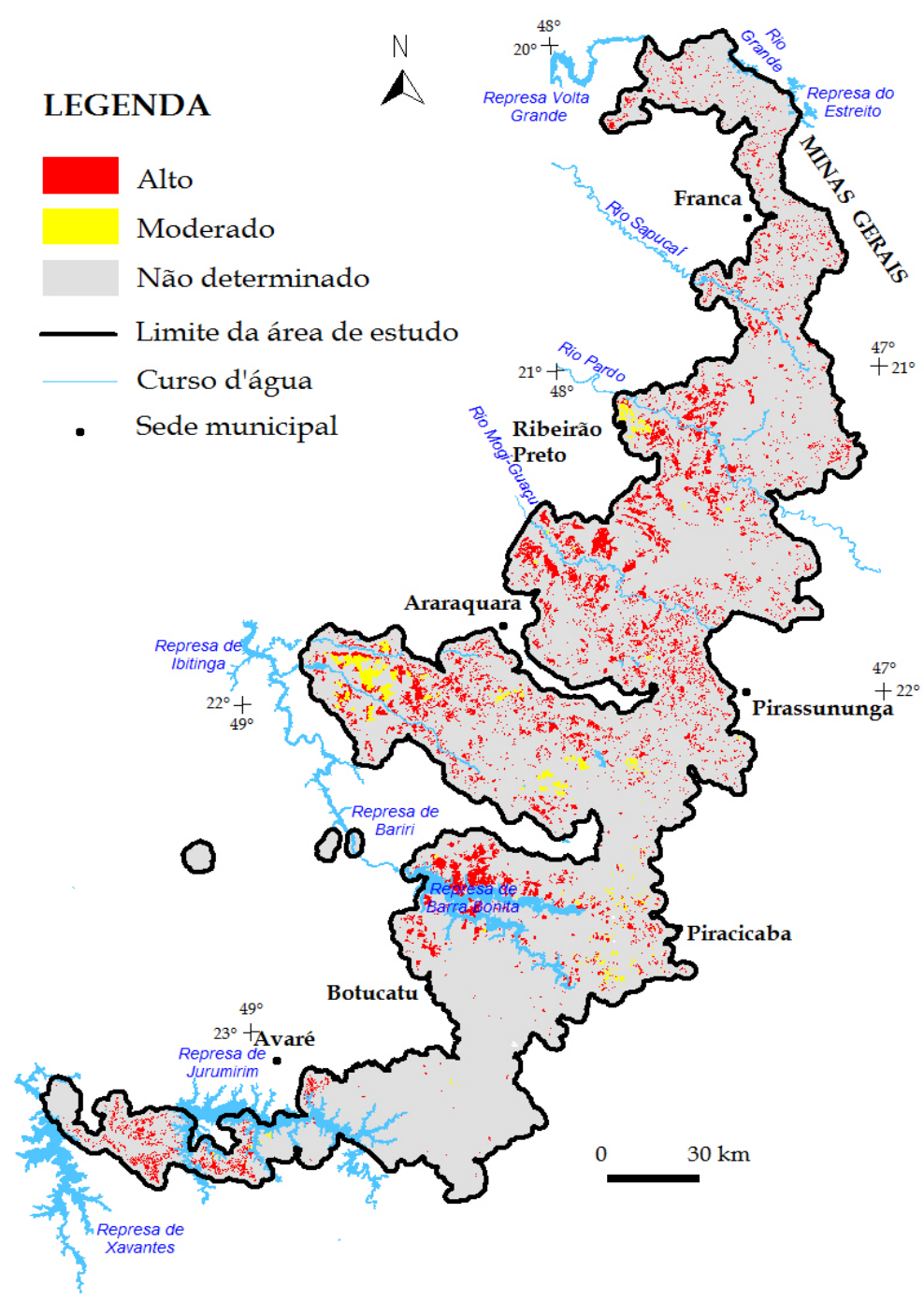

Figura 7. Perigo de Contaminação do SAG decorrente de fontes difusas.

Tabela 3. Perigo de contaminação do SAG decorrente das atividades agrícolas.

\begin{tabular}{|c|c|}
\hline PERIGO DE CONTAMINAÇÃo & $\begin{array}{c}\text { ÁREA } \\
\mathbf{( k m}^{2} \mathbf{)}\end{array}$ \\
\hline Alto & 2.248 \\
\hline Moderado & 281 \\
\hline Não Determinado & 23.581 \\
\hline
\end{tabular}

\section{CONCLUSÕES}

A contaminação dos aquíferos por fontes difusas, notadamente agrotóxicos utilizados na agricultura, ainda é um assunto pouco pesquisado pela comunidade científica devido à complexidade do seu comportamento no ambiente. Nesse sentido a avaliação do perigo de contaminação realizada neste estudo amplia a base de informações e se propõe a contribuir para o estabelecimento de medidas necessárias à proteção das águas do SAG.

Os trabalhos desenvolvidos permitiram caracteri- zar a vulnerabilidade natural à contaminação do SAG na sua área de afloramento no Estado de São Paulo e classificar o potencial de contaminação das águas subterrâneas decorrente das atividades agrícolas existentes na região.

A análise integrada das informações resultou na classificação do perigo de contaminação do SAG decorrente das culturas. Os resultados indicam que o método aplicado mostrou-se uma ferramenta prática para a análise da área estudada, na qual aproximadamente 2.250 $\mathrm{km}^{2}$ foram classificados como de alto perigo de con- 
taminação, perfazendo cerca de $9 \%$ da área de estudo.

Os resultados são úteis como orientação para as ações na área devido ao caráter regional do estudo desenvolvido, sendo imprescindível a realização de estudos de detalhe nas áreas identificadas com alto perigo de contaminação a fim de subsidiar os trabalhos de monitoramento e controle da qualidade das águas subterrâneas.

Considerando o panorama identificado e visando à proteção das águas do SAG é fundamental a adoção de medidas voltadas ao estabelecimento de boas práticas agrícolas em toda a área de afloramento do SAG. Além disso, o zoneamento da vulnerabilidade deve ser utilizado para a análise integrada considerando-se outros tipos de fontes potenciais de contaminação, visto que auxilia a tomada de decisão dos órgãos gestores da qualidade ambiental.

Os estudos realizados são fundamentais para nortear

\section{REFERÊNCIAS BIBLIOGRÁFICAS}

ADAMS,B.;FOSTER,S.S.D.Land-surfacezoningforgroundwater protection. Journal of Institution of Water and

Environmental Management, v. 6, p. 312-320, 1992.

ALBINET, M.; MARGAT, J. Cartographie de la vulnerabilite a la pollution des nappes d'eau souterraine. Bull. BRGM 2me Series, v. 3, n. 4, p. 13-22, 1970.

ALLER, L. et al. DRASTIC: a standardized system for evaluating groundwater pollution potential using hydrogeologic settings, U.S. EPA Report 600/2-85/018. 1987

CAETANO-CHANG, M.R. \& WU, F.T. Bacia do Paraná: formações Pirambóia e Botucatu. In: CONGRESSO BRASILEIRO DE GEOLOGIA, 37, 1992, São Paulo. Roteiro de Excursão... São Paulo: Sociedade Brasileira de Geologia, 1992, v. 2, p. 1-19.

CIVITA, M. et al. Carta de la vulnerabilità all' inquinamento degli acquiferi delle Alpi Apuane. Mem. explic. Monografia GNDCI. - CNR. n. 399, Firenze, 56p. 1990.

COMPANHIA DE TECNOLOGIA DE SANEAMENTO AMBIENTAL - CETESB. Relatório de Qualidade das Águas subterrâneas do Estado de São Paulo 2007-2009. São Paulo: Cetesb, 2010. DEPARTAMENTO DE ÁGUAS E ENERGIA ELÉTRICA - DAEE \& UNIVERSIDADE ESTADUAL PAULISTA - UNESP. Mapa geológico do Estado de São Paulo. Escala 1: 250.000. São Paulo: Convênio DAEE/ UNESP, Secretaria de Obras e do Meio Ambiente do Estado de São Paulo, 1980. (Compilação eletrônica Lebac/ IGCE/ Unesp, 2009).

DUARTE, U. Geologia ambiental da área de São Pedro (SP): vetor águas subterrâneas. (Tese de Doutoramento, IG-USP, inédita). 1980 FOSTER, S. et al. Groundwater quality protection. Washington, D. C: World Bank, 2002. 202 p FOSTER, S. et al. Proteção da qualidade da água subterrânea: um guia para empresas de abasteci- políticas públicas de uso e ocupação territorial, visto que se trata de uma região em crescente desenvolvimento no Estado de São Paulo. O mapa de vulnerabilidade auxilia no planejamento da expansão da ocupação do território e o mapa do perigo indica locais que necessitam de especial controle. Portanto os mapeamentos aqui apresentados devem ser utilizados como subsídio às ações voltadas à proteção desse importante manancial de água subterrânea do Estado de São Paulo.

Outras fontes potencialmente poluidoras de forma difusa ocorrem, também, na área, podendo-se mencionar o saneamento in situ, lançamento no solo de efluentes e resíduos domésticos e de outras atividades (oficinas, pequenas indústrias, postos de serviço, etc.), entre outros, que devem ser objeto de estudo para que se possa, cada vez mais, ampliar as bases técnicas necessárias para a proteção do Sistema Aquífero Guarani em sua área de afloramento.

mento de água, órgãos municipais e agências ambientais. Washington: Banco Mundial, 2006. 104 p. FOSTER, S. S. D. Fundamental concepts in aquifer vulnerability pollution risk and protection strategy. In: INTERNATIONAL CONFERENCE: VULNERABILITY OF SOIL AND GROUNDWATER TO POLLUTANTS, 1987, Noordwijk, Países Baixos. Proceedings... Noordwijk, Países Baixos, 1987. FOSTER, S. S. D.; R. HIRATA. Groundwater pollution risk assessment: a methodology using available data. WHOPAHO/ HPE-CEPIS Technical Manual, Lima, Peru, 1988. GEOGRAPH INFORMÁTICA E SERVIÇOS LTDA. MAPINFO PROFESSIONAL VERSÃO 10.0. Desktop mapping software. GEOGRAPH: MapInfo Corporation, 2009.

GIANINI, P. C. F. et al. Paleoventos e paleocorrentes subaquosas do sistema deposicional Pirambóia nos estados de São Paulo e Paraná, Bacia do Paraná: estudo baseado em análise estatística de dados azimutais. Revista Brasileira de Geociências, v. 34, n. 2, p. 282-292, jun. 2004.

GOMES, M. A.F.(Ed.). Uso agrícola dasáreas de afloramento do Aquífero Guarani no Brasil: implicações para a água subterrânea e propostas de gestão com enfoque agroambiental. Brasília: EMBRAPA, 2008. 417 p.

HIRATA, R.; BASTOS, C. R. A; ROCHA, G. A. (Coords.) Mapeamento da vulnerabilidade e risco de poluição das águas subterrâneas no Estado de São Paulo. São Paulo: IG/ CETESB/DAEE, v.1 e 2, 1997.

INSTITUTO GEOLÓGICO - IG. Companhia de Tecnologia de Saneamento Ambiental - CETESB. Departamento de Águas e Energia Elétrica - DAEE. Mapeamento da vulnerabilidade e risco de poluição das águas subterrâneas no Estado de São Paulo. São Paulo: IG/ Cetesb/ DAEE, 1997. 2 v. mapas. (Série Documentos). 
INSTITUTO DE PESQUISAS TECNOLÓGICAS DO ESTADO DE SÃO PAULO - IPT. Mapa geomorfológico do Estado de São Paulo. Escala 1: 1.000.000. São Paulo: IPT, 1981. 2 v. (Publicação, 1 183; Monografias, 5).

INSTITUTO DE PESQUISAS TECNOLÓGICAS DO ESTADO DE SÃO PAULO - IPT. Diagnóstico Ambiental para Subsídio ao Plano de Desenvolvimento e Proteção Ambiental da Área de Afloramento do Sistema Aquífero Guarani no Estado de São Paulo. São Paulo: IPT, 2010. 7v. 384 p.

MILANI, E. J.; FRANÇA, A. B.; SCHNEIDER, R. L. Bacia do Paraná. Bol. Geociênc. Petro. v. 8, p. 69-82, 1994. ORGANIZAÇÃO DOS ESTADOS AMERICANOS - OEA. Aquífero Guarani: programa estratégico de ação = Acuífero Guaraní: programa estatégico de acción. Edição bilíngue. OEA: Brasil; Argentina; Paraguai; Uruguai, 2009. 424 p.

RIBEIRO, M. L. et al. Contaminação de águas subterrâneas por pesticidas: avaliação preliminar. Revista Química Nova, v. 30, n. 3, p. 688-694, maio/junho. 2007.

ROCHA, G. A. (Coord.). Mapa de águas subterrâneas do Estado de São Paulo - escala 1: 1.000.000. São Paulo: DAEE/ IG/ IPT/ CPRM, 2005. 119 p. SECRETARIA DE ESTADO DO MEIO AMBIENTE - SMA. Mapeamento do uso e ocupação do solo no Estado de São Paulo. São Paulo: SMA, 2009. TALTASSE, P. Mapas de vulnerabilidade à poluição dos lençóis aquíferos do município de Campinas (SP). Universidade de São Paulo (IGc). Publ. Avulsa n.1. 1972

\section{AGRADECIMENTOS}

Julga-se oportuno agradecer ao Fundo Estadual de Recursos Hídricos (Fehidro) pelo apoio financeiro, por intermédio do Comitê Coordenador do Plano Estadual de Recursos Hídricos (CORHI) e da Secretaria do Estado de Meio Ambiente (SMA)/Coordenadoria de Planejamento Ambiental (CPLA), ao Projeto Diagnóstico Ambiental para Subsídio ao Plano de Desenvolvimento e Proteção Ambiental da área de afloramento do Sistema Aquífero Guarani no Estado de São Paulo. Agradece-se, também, ao Serviço Geológico do Brasil (CPRM) e ao Grupo de Acompanhamento Técnico (GAT) do Projeto, composto por representantes da Secretaria de Estado do Meio Ambiente (SMA) - com representantes da Coordenadoria de Planejamento Ambiental (CPLA), por intermédio do seu Departamento de Planejamento Ambiental; da Coordenadoria de Recursos Hídricos (CRHi); da Companhia Ambiental do Estado de São Paulo (Cetesb); e do Instituto Geológico (IG); e da Secretaria de Estado de Saneamento e Energia (SSE) - com representantes do Departamento de Águas e Energia Elétrica (DAEE). 